\title{
STATE DETERMINED SYSTEM OF A CIRCADIAN RHYTHM IN SCORPION
}

\author{
BY T. RAMAKRISHNA* \\ (Department of Zoology, Sri Venkateswara University, Tirupati, A.P.) \\ AND \\ Kandula Pampapathi RaO \\ (Department of Zoology, Bangalore University, Bangalore-1) \\ Received July 16, 1970 \\ (Communicated by Dr. H. Srinivasa Rao, F.A.Sc.)
}

\section{INTRODUCTION}

EXTENSIVE studies have been made of the endogenous rhythms in neurosecretion (Habibullah, 1963) in the central excitability state (Rao, K. P., 1963; 1964, Rao and Gopalakrishna Reddy, 1967) and in the locomotory and respiratory activities (Gopalakrishna Reddy, 1966) of the scorpion, Heterometrus fulvipes. These studies have assumed a new dimension in view of the growing realisation of the importance of photoreceptors in relation to the central auto-rhythmicity (Rao, K. P., 1968; Ramakrishna and Rao, 1970; Uwo and Pittendrigh, 1968; Kupferman, 1968; Jacklet, 1969). Primarily in search of this relationship, photic behaviour of the scorpion, H. fulvipes, was studied in the laboratory through a $24 \mathrm{hr}$. period.

\section{Material AND Methods}

Two types of chambers were used in separate experiments for the purpose (Fig. 1). Type I consisted of two chambers, each measuring $27^{\prime \prime} \times 7^{\prime \prime}$ $\times 4^{\prime \prime}$. The partition in the middle had a slit of the size of $3^{\prime \prime} \times 1^{\prime \prime}$. Type II consisted of four such chambers, radiating from a small middle chamber of the size, $7^{\prime \prime} \times 7^{\prime \prime} \times 4^{\prime \prime}$. Each wall of the middle chamber had an entrance of the size of $3^{n} \times 1^{\prime \prime}$. A 100-watt light bulb was suspended in the middle in either case at a height of two feet. Each chamber had a different intensity from that of the other which was provided by means of neutral density filters, spread over the glass roof of each chambcr. The chamber without

* Present Address: Department of Biophysics, All-India Institute of Mental Health, Bangalore-27. 
a filter was considered to have unit intensity and the one with a dark coated glass roof was considered to have 0 intensity. The intermediate intensities of 0.5 and 0.25 were provided by one and two layers, respectively, of the neutral density filter. Thus in Type I chamber, two different intensities were provided whereas in type II four different intensities could be provided.
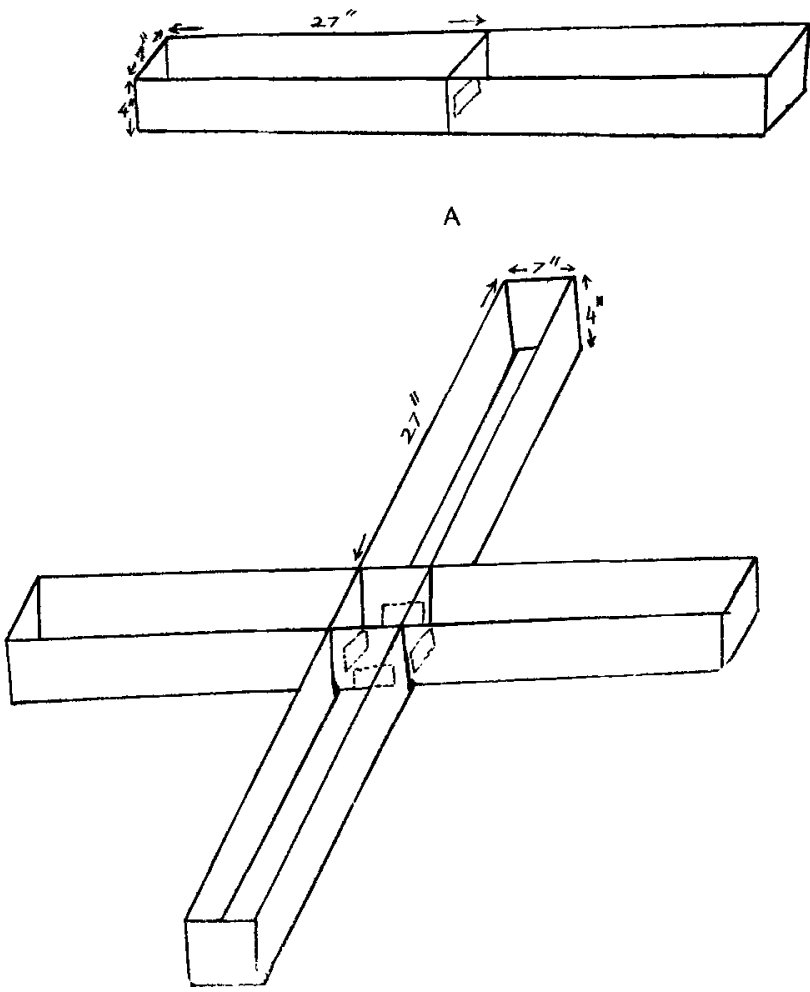

Fig. 1. Choice-chambers used to record the photic response of the scorpion. (A, Two chambers; B, Four chambers.)

In separate experiments a wide range of intensity scales were used, in the case of Type $I$ chamber, such as 1 and $0 ; 0.5$ and $0.25 ; 0.5$ and 0.125 and 1 and 1 for control. The intensity scale in Type II chamber included $1,0.5,0.25$ and 0 ; as well as unit intensity $(1,1,1$ and 1$)$ in all for control. In any given experiment, ten scorpions were used in Type 1 and twenty were used in type II chamber. The number of scorpions in each chamber was noted at the interval of two hours over a period of four consecutive days. In all 14,448 such position recordings were obtained. 'Photic-response' curves were drawn for each set of scorpions used in every 
experiment by plotting the percentage of animals in each intensity, expressed as $\%$ preference against the time of the day.

\section{Results AND Discussion}

The results indicated an apparent reversal in the sign of photic response of the scorpion, H. fulvipes, in that there was alternating preference to the extremes of the intensity scale provided. The scorpion seemed to be photopositive during the evening between $6 \mathrm{p}$.m. and 12 midnight whereas they appeared to become photonegative around 12 midnight (Fig. 2).

The scorpion, $H$. fulvipes, is known to live underneath the stones in deep burrows at a depth of about one to two feet. They leave the dark daytime shelters and come out to the open during the evening and early part of the night in search of food and other requirements. It is obvious that even during a dark night, an exposed area will be relatively brightly lit when compared to an enclosed space such as the deep burrows where scorpions remain during daytime. It follows then that the scorpion moves out into comparatively higher levels of illumination at dusk and returns into much lower levels of illumination before dawn. Significantly, the preference of the scorpion for higher levels of light-intensity falls within the period in which its locomotor activity is at a higher level. The stimulating effect of light on the nervous system in general and on the locomotor activity in particular, is well known (Gopalakrishna Reddy, 1966; Herms, 1911; Patten, 1917; Pardi and Papi, 1961). Besides, the photo-positive response of the scorpion falls within the duration during which the central nervous system (CNS) is at a higher level of excitability. While the CNS shows high activity between 4 p.m. and 11 p.m., it is significant that the scorpion exhibits maximal preference for higher levels of light-intensity between 6 p.m. and 10 p.m. but never beyond 12 midnight.

Based on the assumption that the mathematical ratio between the central excitability and the non-specific sensory input is maintained at an approximately constant level, it has been suggested that a dynamic equilibrium exists between the two (Rao, K. P., 1968; Ramakrishna and Rao, 1970). According to Ashby (1956):

(i) A line of behaviour is specified by a succession of states and the time intervals between them;

(ii) two lines of behaviour are equal if all the corresponding states and time intervals along the succession are equal; and 
(iii) If all the lines of behaviour that follow an initial state, $S$ are equal, and if a similar equality occurs after every other state, $\mathbf{S}^{\prime}, \mathbf{S}^{\prime \prime} \ldots$ then the system is regular. The photic behaviour of the scorpion conforms to these laws and can be represented by equations of the form:

$$
\begin{aligned}
& x_{1}=\mathrm{R}\left(\mathrm{Z}_{1} \ldots \mathrm{Z} n ; t\right) \text { and } \\
& x_{2}=\mathrm{R}\left(\mathrm{Z}_{1} \ldots \mathrm{Z} n ; t\right) \text { and so on. }
\end{aligned}
$$

Similarly,

$$
\begin{aligned}
& y_{1}=\mathrm{R}\left(\mathrm{Z}_{1} \ldots \mathrm{Zn} ; t\right) \text { and } \\
& y_{2}=\mathrm{R}\left(\mathrm{Z}_{1} \ldots \mathrm{Zn} ; t\right) \text { and so on }
\end{aligned}
$$

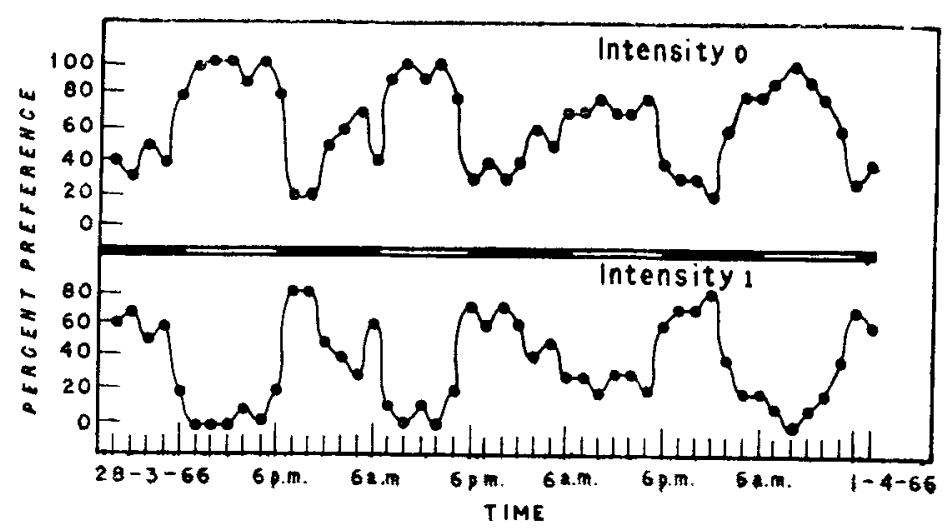

Fig. 2. A typical photic-response curve of the scorpion, obtained through a two chamber technique.

where

$x$ and $y$ correspond to the central excitability states,

$\mathrm{R}$-the ratio between the central excitability state and the tonic sensory input which is relatively constant,

$\mathrm{Z}_{1} \ldots \mathrm{Zn}$ - tonic sensory input from different sense-organs, where $n$ is finite,

$t$-time at which the variables $\mathrm{Z}_{1} \ldots . \mathrm{Zn}$ operate.

The mathematical expression, given to the relation between photic behaviour and the autorhythmicity in the central excitability, thus provides a theoretical basis as to how a dynamic equilibrium can possibly be maintained between the tonic sensory input and the central excitability 
state. The excursion of the scorpion to the open during nights exposes it to much more complex stimulus-situation in general, when compared to its daytime shelter. This might result in an increment of the tonic sensory input from different sense-organs, corresponding to the time when the central excitability is at a higher level. What happens after midnight is just the reversal of this phenomenon, as is diagrammatically represented (Fig. 3).

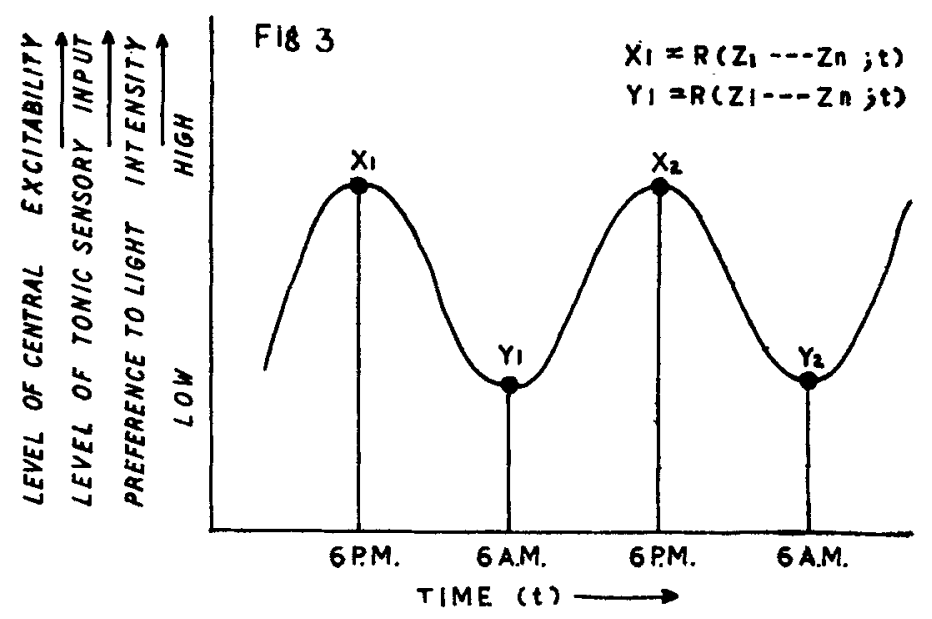

Frg. 3. Photic behaviour of the scorpion, operating on the lines of state-determined system, as described by Ashby (1956).

\section{ACKNOWLEDGEMENT}

We thank Miss Biederman-Thorson and Dr. John M. Palka for the gift of neutral density filters. This investigation has been supported by grants from USAFOSR to Prof. K. Pampapathi Rao.

\section{REFERENCES}

1. Ashby, W. R.

.. Introduction to Cybernetics, Chapman and Hall, London, 1956.

2. Gopalakrishna Reddy, T. . . Doctoral Thesis, Sri Venkateswara University, 1966.

3. Md. Habibullah _. Ibid., 1963.

4. Herms, W. B. ․ J. Exp. Zool., 1911, 10, 167.

5. Jacklet, J. W. $\quad$. Science, 1969, 164, 562.

6. Kupferman, I. $\quad \ldots \quad$ Physiology and Behaviour, 1968, 3, 179.

7. Pardi, L. and Papi, F. _. In The Physiology of Crustacea, Waterman. T. H., Ed., Academic Press, New York, 1961. 
8. Patten, B. M.

9. Ramakrishna, $T$. and Rao, K. P.

10. Rao, K. P.

11.

12.

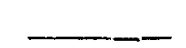

.. J. Exp. Zool., 1917, 23, 251. Ind. J. Exptl. Biol., 1970, 8, 337.

.. Proc. XVI Internatl. Congress of Zoology, 1963.

.. J. Animal Morphol. Physiol., 1964, 11, 133.

.. Proc. XXIV Internatl. Congress of Physiol. Sci., 1968, 7, 335.

13. _ـ and Gopalakrishna Reddy, $T$.

14. Uwo, J. N. and Pittendrigh, Zeit. vergl. Physiol., 1968, 58, 14.

Nature, 1967, 213, 1047. 